\title{
A Comparative Study on Sentence Translation of Two Chinese Versions of The Great Gatsby
}

\author{
HUANG Jing, GUO Ting-pei \\ School of Foreign Languages, China West Normal University, Nanchong, China
}

The Great Gatsby is an epitome of America in the 1920s. Among various Chinese versions, Wu Ningkun's and Yao Naiqiang's versions have gained wild acceptance. This paper studies their similarities in simple sentence, compound and complex sentence, as well as differences in word order and sentence segmentation. Furthermore, this paper studies similarities and differences of Wu's and Yao's sentence translation on the basis of Nida's Functional Equivalence (FE).

Keywords: functional equivalence, The Great Gatsby, sentence translation

\section{Introduction}

The Great Gatsby, written by F. Scott Fitzgerald in 1925, is a typical work of "The Lost Generation”. The author not only depicts the extravagant life of an emerging industrial city Detroit after WWI, but also depicts the decadent culture after WWI, creating a portrait of the Jazz Age or the Roaring Twenties.

This typical literary work of "The Lost Generation" has been translated into more than five Chinese versions since the late 1950s. Among various Chinese versions, Wu Ningkun’s and Yao Naiqiang’s versions have gained more popularity and acceptance. The version of Wu Ningkun, translated in 1982, is one of the most famous Chinese translation of The Great Gatsby, as well as one of the wildest spread version which has set the tone of later translations; meanwhile, the version of Yao Naiqiang, translated in 2003, has gained its popularity for its distinct language style.

\section{Translation Theory: Functional Equivalence}

Eugene A. Nida, a founder of modern translation theory, proposes Functional Equivalence (FE) which means that target language (TL) should be equal to source language (SL) in lingual function instead of form. Nida's Functional Equivalence brings out a new perspective of translation theories in last century. In Nida's opinion, translation should reproduce message of SL in a most natural way-firstly translate the meaning of SL, then the style (Eugene, 2003).

Functional Equivalence doesn't simply mean lingual equivalence. FE is the equivalence of readers' psychological reactions, which means that the TL readers have the same experience as SL readers do while reading. In a nutshell, it is safe to summarize his theory into three parts: (1) abandon traditional concepts about parts of speech; (2) use kernel sentence to help readers to get rid of syntactic barricade; (3) use isomorphism to get over cultural discrepancy (YE, 2013, p. 151). 


\section{Comparison of Wu's and Yao's Sentence Translations}

\section{Similarities}

As the popular Chinese versions of The Great Gatsby, Wu's and Yao's translations have many parts in common, such as their dictions, paragraphs, styles, and especially their sentence translations. Studying Wu's and Yao's similarities in sentence translation is conducive to know how they understand and reproduce the original text. Moreover, it is beneficial to translation practice. Wu and Yao have many merits in their sentence translations. As many scholars have praised Wu's and Yao's excellent translations in their papers, this paper would not like to repeat but to focus on their controversial translations. To analyze Wu's and Yao's similarities in sentence translation, this paper exemplifies simple sentence, as well as complex and compound sentence.

Simple sentence. In simple sentence, $\mathrm{Wu}$ and Yao are not flexible enough to change word order which leads to syntactic barricade for TL readers. There are some translations which cannot conform to Chinese linguistic conventions. The example is as follows.

(1) “Meyer Wolfsheim's name wasn’t in the phone book.” (Fitzgerald, 2012, p. 206, para. 2)

Wu’s translation: “迈尔.沃尔夫山姆的名字不在电话簿里”

Yao’s translation: “迈尔.沃尔夫山姆的名字不在电话簿里”

$\mathrm{Wu}$ and Yao translate in accordance with the order of the original text. However, it is preferred in Chinese linguistic conventions, the expression of “电话簿里没有迈尔.沃尔夫山姆的名字”, which changes the subject from name to the phone book, is better than “迈尔.沃尔夫山姆的名字不在电话簿里”. Changing subjects can be an effective way in English to Chinese (E-C) translation. When translating, in order to adapt to TL linguistic conventions, translators are supposed to be flexible enough to change word order, especially subjects and objects.

Compound and complex sentence. Not only in simple sentence, but also in compound and complex sentence, $\mathrm{Wu}$ and Yao also cannot be flexible enough to change word order. They translate the text in verbatim form of The Great Gatsby, which causes syntactic barricade to TL readers. There’s an example as follows.

(1) "This has been one of the most terrible shocks of my life to me, and I hardly can believe it that it is true at all.” (Fitzgerald, 2012, p. 207, para. 4)

Wu’s translation: “这个消息使我感到万分震惊, 我几乎不敢相信这是真的”

Yao’s translation: “这个消息使我感到万分震惊, 我几乎不敢相信这是真的”

There are two controversial points in this sentence translation. Firstly, translating "the most terrible shocks" into the main sentence's subject or object. Wu and Yao both make "the most terrible shocks" the subject in Chinese version. However, according to Chinese linguistic conventions, person like "I", "he", and "she" being set as the subject of a sentence is the better expression rather than thing. Thus, it is safe to say that “听到这个消息我感到万分震惊, 几乎不敢相信这是真的” can be a better translation. Different from the frequently used passive patterns in English, Chinese rarely make thing subject to constitute a passive sentence. Too many passive patterns can cause comprehension disorder for Chinese readers. Secondly, there is a mixture of subjects in Chinese version. In Chinese version, the subject in first clause is “这个消息” (“the most terrible shocks”), the subject in second clause is “我” (“I”). In accordance with Chinese syntactic rule, there is only one subject in one sentence. Therefore, Wu's and Yao's translation of this sentence fails to achieve functional equivalence. 


\section{Differences}

SL and TL, especially Chinese and English which are two unrelated languages, have great differences of their sentence patterns. For instance, English prefers long and difficult sentences together with various subordinate clauses, while Chinese prefers short and simple sentences. English is a language of hypotaxis which focuses on logic and form, while Chinese is a language of parataxis which focuses on description and meaning. Therefore, in E-C translation, translators are supposed to be proficient in SL syntax to understand the original text, and be proficient in TL syntax to reproduce the original text in an acceptable way. Moreover, in sentence translation, translators are supposed to grasp differences of SL's and TL's sentences. Otherwise, TL readers cannot understand the literary work as SL readers do. As a result, the translation fails to achieve FE.

There are two major differences between Wu's and Yao's sentence translation-word order in a sentence, and segmentation of a long sentence. This paper exemplifies word order in sentences and segmentation of long sentences as follows:

Word order. First of all, discrepancy in word order of a sentence is evident in Wu's and Yao's versions. Changing the word order can cause the variation of emphasis in a sentence, as well as barricade of understanding. The examples below demonstrate that different word order can cause the variation of emphasis in a sentence.

(1) “He was crazy enough to kill me if I hadn’t told him who owned the car.” (Fitzgerald, 2012, p. 222, para. 6)

Wu’s translation: “他已经疯狂到可以杀死我的地步, 要是我没告诉他那辆车是谁的”

Yao’s translation: ”要是我不告诉他那辆车是谁的, 他会气疯到了非把我杀了不可的地步”

When translating “He was crazy enough to kill me”, Wu sets “他已经疯狂到可以杀死我的地步” at the beginning of his sentence, while Yao puts “他会气疯到了非把我杀了不可的地步” at the end. As a result, Wu's translation emphasizes on "if I hadn't told him”, and Yao's translation emphasizes on "He was crazy enough to kill me". Obviously, the emphasis of author is on "He was crazy enough to kill me" instead of "if I hadn't told him who owned the car", due to "if" clause is less important than main clause in English. Thus, Yao's translation is closer to the original text. Moreover, Chinese prefers to put key information at the end of a sentence. Hence, Yao, setting “他会气疯到了非把我杀了不可的地步” at the end, does a better translation than $\mathrm{Wu}$ in view of FE. The variation of word order changes emphasis of a sentence.

(2) "He was so hard up he had to keep on wearing his uniform because he couldn't buy some regular clothes.” (Fitzgerald, 2012, p. 214, para.1)

Wu's translation: “他穷得只好继续穿军服, 因为他买不起便服”

Yao’s translation: “他手头十分拮据, 买不起便服, 只好继续穿军服”

Wu sets “军服” before “便服”, which emphasizes the reason why Gatsby kept wearing his uniform. At the same time, Yao sets “便服” before “军服” to show that Gatsby is too poor to buy some regular clothes. Again, this example demonstrates that different word order can change the emphasis of one sentence. In accordance with English linguistic conventions, it is easy to find out that English writers prefer to set key words at the beginning of a sentence, thus, in this example, the author's emphasis is supposed to be "He was so hard up” which means that Gatsby is too poor. In this way, Wu's translation is closer to original text.

(3) "When I had finished she told me without comment that she was engaged into another man" (Fitzgerald, 2012, p. 220, para. 4) 
Wu's translation: “她告诉我她和另外一个人订婚了, 别的话一句没说”

Yao's translation: “她不作任何评说, 只对我说她和另外一个人订婚了”

On the basis of English linguistic conventions, prepositional phrases setting as complements, adverbials and attributes are less essential than noun phrases and verb phrases in a sentence. Thus, the emphasis of the sentence is supposed to be “she told me without comment”. When translating, Wu sets “别的话一句没说” (she told me without comment) at the end of his sentence, while Yao puts “她不作任何评说” (she told me without comment) at the beginning. Wu's translation emphasizes on "without comment”, and Yao's translation emphasizes on "she was engaged into another man". Apparently, Wu's translation is closer to the original text. In a word, the change of word order can dissimilate the emphasis of a sentence.

All examples above show that Wu and Yao have different emphasis in some sentence translations. And the change of word order can vary the emphasis of a sentence.

Sentence segmentation. Different sentence segmentation determines ease of reading. Too little segmentation may make a long sentence cumbersome. Too much segmentation may make a sentence loose. Inappropriate sentence segmentation can cause different syntactic barricade to TL readers.

(1) “West Egg, especially, still figures in my more fantastic dreams” (Fitzgerald, 2012, p. 220, para. 1)

Wu's translation: “西卵依然出现在我做的比较荒唐的梦里”

Yao's translation: “那个地方, 在我做的许多古怪的梦里经常会出现它”

Wu translates "West Egg” into “西卵” and puts it at the beginning of the sentence which makes it the subject in this sentence, while Yao translates “West Egg” into two pronouns “那个地方” and “它” and puts them at the beginning and end respectively which makes it the object in this sentence. On the one hand, two pronouns in a sentence make Yao's translation more complicate than Wu's translation for TL readers to understand. On the other hand, in original text author uses "especially" to emphasize "West Egg", and Yao uses two pronouns to emphasize the same thing. However, in Wu's translation, there is no emphasis on "West Egg". Yao's translation is more complex and cumbersome than Wu's translation, but it reproduces the original text's message completely. In the light of integrality of message, Yao's translation serves FE better.

(2) "and when he looked around him now for the first time and saw the height and splendor of the hall and the great rooms opening out from it into other rooms” (Fitzgerald, 2012, pp. 209-210, para. 1)

Wu's translation: “于是此刻他第一次向四周一望, 看见门厅如此富丽堂皇, 一间一间大屋子从这里 又通向别的屋子”

Yao’s translation: “于是此刻他第一次向四周张望, 看见门厅如此富丽堂皇，从这里通向一间间大房 间, 又通向别的房间”

For readers, Wu's and Yao's translation in this sentence is too cumbersome to understand. In the original sentence, there are four sense groups: he looked around for the first time; he saw that the hall is high and splendid; the hall connects with great rooms; great rooms connect with other rooms. In Yao's translation, the subject of the last clause is omitted, which makes disorder of subjects. It is hard to find out whether the hall or the great rooms is the subject of the last clause. As for $\mathrm{Wu}$, he combines last two clauses together and makes subject clear. Although Wu makes less segmentation, he makes his meaning more clear. The point of making segmentation is to make sense group clear, and Wu does better in this sentence translation.

Word order and sentence segmentation are two major differences among their sentence translations. Changing word order can cause variation of a sentence's emphasis, as well as barricade for TL readers to understand. As for sentence segmentation, too little segmentation may make a long sentence cumbersome, and 
too much segmentation may make a sentence loose. For TL reader's better understanding, translators must be careful and flexible.

\section{Conclusion and Implication}

\section{Conclusion}

In this paper, comparative study between Wu Ningkun's and Yao Naiqiang’s versions has been done on the basis of sentence translation.

Studying Wu's and Yao's similarities in sentence translation is conducive to know how they understand and reproduce the original text, as well as their styles of translation. Moreover, it is beneficial to translation practices. On the one hand, $\mathrm{Wu}$ and Yao have many merits in their sentence translations. For example, they both do well in changing word order and making sentence segmentation. On the other hand, they both make some controversial translations. In simple sentence, $\mathrm{Wu}$ and Yao are not flexible enough to change word order, which leads to syntactic barricade for TL readers. Not only in simple sentence, but also in compound and complex sentence, $\mathrm{Wu}$ and Yao also cannot be flexible enough to change word order. They translate the text as the same order of The Great Gatsby in original version, which cannot conform to Chinese linguistic conventions.

Studying on differences of Wu's and Yao's sentence translation is an indispensable step to know their translation ability, translation styles and whether they have achieved FE or not. It is also conducive to translation practices. English is a language of hypotaxis which focuses on logic and form, while Chinese is a language of parataxis which focuses on description and meaning. In Wu's and Yao's translation, word order and sentence segmentation are two major differences. Changing word order can cause emphasis of a sentence to change, as well as barricade for TL readers to understand. As for sentence segmentation, for TL readers' better understanding, translators ought to make segmentation carefully in lines with author's intention, combine related clauses together to form a relatively complete meaning, and be flexible to make segmentations.

To sum up, study on similarities and differences can help researchers with exploring whether $\mathrm{Wu}$ and Yao have achieved FE. According to Functional Equivalence, the standard of good translation is that the translation work can cause the same reaction as SL readers. Thus, translators are supposed to be familiar with TL's and SL's linguistic conventions to achieve FE.

\section{Implication}

In light of comparative study of Wu's and Yao's sentence translation, three tips are concluded for future translation.

First of all, in sentence translation, translators are supposed to be familiar with TL's and SL's linguistic conventions. For instance, Chinese prefers person as subject, instead of thing. Moreover, English prefers to put key information at the very beginning of a sentence, while Chinese prefers to put it at the end. Knowing different features of different language is conducive for translator to achieve FE.

Moreover, in sentence translations, if necessary, translators should try to be flexible in changing word order or making sentence segmentation in lines with TL linguistic conventions. Changing word order can vary different emphasis of a sentence, while changing sentence segmentation can make translation easier or more difficult for TL readers. Thus, deliberate choices should be done during the course of translation. 
At last, when translating, translators are supposed to pay more attention to the whole style of authentic text. Translators cannot change or even reverse author's style at random. To follow author's style, translators need to read the original text several times, as well as collect background information.

In a nutshell, translation is an art which needs diligent effort and abundant background information. To achieve Functional Equivalence, sentence pattern should be chosen deliberately so that the same reaction of SL readers can be reached by TL readers.

\section{References}

Eugene, N. (2003). The theory and practice of translation. Leiden: Brill Academic Pub. Fitzgerald, F. S. (2012). The Great Gatsby. Nanjing: Yilin Press.

WU, N. K. (1983). 菲茨杰拉德小说选 (The collected novels of Fitzgerald). Shanghai: Shanghai Translation Publishing House. YAO, N. Q. (2004). 了不起的盖茨比 (The Great Gatsby). Beijing: People’s Literature Publishing House.

YE, Z. N. (2013). 高级英汉翻译理论与实践 (Advanced English-Chinese translation theory and practice). Beijing: Tsinghua University Press. 